\title{
Kearifan Lokal dalam Hibriditas Sastra Indonesia Modern
}

\author{
Redyanto Noor \\ Fakultas Ilmu Budaya, Universitas Diponegoro \\ redyanto@lecturer.undip.ac.id
}

\begin{abstract}
Information technology causes cultural transformation that makes global culture is formed. Cultural products called local-genius (local wisdom) are increasingly rare, including art and literature. Classical literature is no longer lived as the orientation of the great values of the past, but is considered a cultural artifact. For modern literature when an author recognizes new conventions and values in his mind, then when he perceives and creates them into literary works, in fact he has made hybrid literature. In biology, hybrid is the result of crossing between one species with another species, naturally or through manipulation. If you look at the origins of language and literature, modern literature is actually hybrid literature, we called modern Indonesian. Really, modern Indonesian author were limited to updating the disclosure method. Basically they remain grounded in the traditions and culture that gave birth to them, which have local-genius (localwisdom).
\end{abstract}

Keywords: Hybrid literature; local wisdom; tradition; culture.

\section{Intisari}

Teknologi informasi menyebabkan terjadi transformasi kebudayaan sehingga terbentuk kebudayaan global. Produk kebudayaan yang disebut local-genius (kearifan lokal) semakin langka, termasuk seni dan sastra. Sastra klasik tidak lagi dihayati sebagai orientasi nilai-nilai masa lampau yang agung, tetapi dianggap sebagai artefak kebudayaan. Bagi sastra modern ketika seorang pengarang mengenal konvensi dan nlai-nilai baru dalam pikirannya, maka ketika ia meresepsi dan mengkreasinya menjadi karya sastra sesungguhnya ia telah membuat sastra hibrida. Dalam ilmu biologi hibrida adalah hasil penyilangan antara satu spesies dengan spesies lain, secara alamiah atau melalui rekayasa. Sebenarnya sastra modern adalah sastra hibrida, hasil penyilangan dari berbagai bahasa dan kebudayaan termasuk sastra Indonesia modern. Meskipun, sebenarnya sastra hibrida tetap mengakar pada budaya etnik penciptanya. Pengarang sastra Indonesia modern sebenarnya hanya sebatas memperbarui cara pengungkapan. Secara esensial mereka tetap berpijak pada tradisi dan budaya yang melahirkannya, yang memiliki local-genius (kearifan local).

Kata kunci: Sastra hibrida; kearifan lokal; tradisi; kebudayaan. 


\section{Pendahuluan}

Era teknologi informasi telah me-reunifikasi-kan manusia sejagad dalam proses transformasi kebudayaan sehingga terbentuk sebuah kebudayaan global. Produk kebudayaan dengan label local-genius (kearifan lokal) semakin langka, termasuk seni dan sastra. Sastra klasik tidak lagi dihayati sebagai orientasi memahami nilai-nilai masa silam yang dipandang luhur dan agung. Sikap modern memandang sastra klasik sebagai artefak kebudayaan dan kesejarahan yang harus dibaca secara diakronis, agar ia tidak kehilangan relevansi maknanya. Sebagaimana dikatakan Damono bahwa struktur dan masalah sastra yang semakin rumit sekarang ini tidak dapat dipisahkan dari semakin rumitnya struktur dan masalah sosial-budaya masyarakat yang melahirkan sastra itu. Sebab, problem sosial manusia masa lampau tidak serumit problem sosial manusia masa sekarang (2009:6-7).

Sejak awal sastra telah tercipta dalam bentuk hibrida. Di saat seorang pengarang mengenal konvensi dan nlai-nilai baru tentang apa saja dalam pikirannya, maka ketika ia meresepsi dan mengkreasinya menjadi karya sastra sesungguhnya ia telah membuat sastra hibrida. Semakin rumit konvensi dan nilai-nilai baru yang diterima seorang pengarang, semakin rumit pula ia terlibat proses resepsi dan kreasi mencipta sastra. Kerumitan itu tidak terbatas pada gagasan dan kisah yang diungkapkannya, tetapi juga menyangkut bahasanya (Damono, 1999:8-9). Bahasa mengalami evolusi terus-menerus, beberapa kali ia mengalami revolusi yang membawa perubahan penting terhadap cara dan gaya manusia berkomunikasi, yakni ketika pertama kali ditemukan tulisan, ditemukan mesin cetak, dan ditemukan teknologi informasi. Implikasi evolusi dan revolusi bahasa pada sastra tidak hanya pada gagasan dan persoalan yang diungkapkan, tetapi juga menyangkut bahasa pengungkapannya, menjadikan sastra semakin hybrid (Noor, 2014:19).

Persoalan seputar sastra hibrida adalah bahwa masyarakat sekarang dihadapkan pada realitas perkembangan penciptaan dan penyebarluasan sastra yang membawa aneka ragam benda (visual dan audio) yang serba belum jelas identitasnya: sastra instalasi, sastra cyber, sastra graffity, sastra flash, sastra facebook, sastra twitter, sastra blog, sastra diary, sastra cinema, sastra electronic, sastra science, sastra digital (Noor, 2014:26). Seolah-olah sastra kontemporer telah dibanjiri bermacam-macam sastra kreasi baru, yang berbeda satu dengan 
lainnya. Persoalannya adalah eksistensi sastra cyber selalu dikaitkan dengan ukuran "estetika", yang menurut sebagian ahli sastra tidak sepadan dengan sastra buku, sastra koran, sastra majalah yang memiliki estetika esensial dan bisa diukur. Terlebih-lebih apabila dikaitkan dengan istilah local genius (kearifan lokal), maka seolah-olah bentuk-bentuk sastra modern itu dianggap kosong.

\section{Metode Penelitian}

Metode yang digunakan adalah sosiologi sastra, karena masalah kearifan lokal dan sastra hibrida adalah salah satu aspek sosial dalam karya sastra. Sastra hibrida masa sekarang dianggap sebagai revolusi penciptaan dan penyebarluasan sastra, sebagaimana internet dianggap revolusi media ketiga setelah penemuan huruf tulis, mesin cetak, dan media elektronik (Damono, 2009:12). Sejak awal munculnya sastra hibrida, sebenarnya sastra telah memiliki beberapa kekhasan yang terkait dengan keberadaan teknologi media. Antara lain sastra buku, sastra majalah, sastra koran, dan sebagainya (Noor, 2014:23). Ketika biaya publikasi sastra semakin mahal, dan sastra buku/koran/majalah telah membangun hegemoninya sendiri, tiba-tiba datang IT (teknologi informasi). Lahirlah bentuk-bentuk baru sastra seperti sastra instalasi, sastra cyber, sastra graffity, sastra facebook, sastra twitter, sastra blog, sastra diary, sastra flash, sastra cinema, sastra electronic, sastra science, sastra digital, sastra science, dan sebagainya. Ironisnya, tantangan yang muncul justru dari dunia sastra sendiri. Salah satu contoh, misalnya sastra cyber pernah dianggap sebagai sekadar ajang bermain-main sehingga kualitas kesastraannya sangat diragukan. Sebenarnya penggunaan istilah sastra cyber jelas menyatakan jenis medium yang dipakai: medium cyber, sama halnya dengan istilah sastra buku, sastra koran, sastra majalah, dan sebagainya (Noor, 2014:24). Jadi, semua sastra yang dipublikasikan melalui medium cyber dapat disebut sastra cyber.

\section{Hasil dan Pembahasan}

\section{Hibriditas Sastra Modern}

Sastra Indonesia tidak dapat dipisahkan dari bahasa Indonesia. Bahasa Indonesia menjalankan fungsi dan menempati kedudukan aneh dalam masyarakat. Ia berasal dari bahasa Melayu yang 
dikembangkan dan digunakan oleh masyarakat, yang sebagian besar bukan penutur aslinya. Kenyataan ini merupakan inti persoalan perkembangan sastra Indonesia modern. Masyarakat Indonesia sepakat menerima bahasa Indonesia sebagai bahasa persatuan, sementara itu tiaptiap kelompok etnis berusaha sebaik-baiknya untuk tidak meninggalkan kebudayaan yang berkaitan dengan bahasa etnisnya. Menurut Damono, dalam ketegangan antara kesepakatan kuat untuk menjadi Indonesia dan keterikatan pada kebudayaan daerah itu lahir sastra Indonesia modern. Sastra Indonesia baru itu adalah sastra hibrida (1999:vii).

Dalam Encyclopedia Botanica dijelaskan bahwa hibrida adalah hasil penyilangan antara satu spesies dengan spesies lain. Proses penyilangan itu dapat berlangsung secara alamiah atau melalui rekayasa. Secara alamiah penyilangan berlangsung evolusioner dengan tingkat keberhasilan yang rendah karena seleksi alam yang ketat, sedang penyilangan rekayasa dapat berlangsung revolusioner, apalagi jika direkayasa dengan teknologi. Fungsi penyilangan itu untuk meningkatkan kualitas dan keberagaman genetik. Oleh sebab itu, hibrida memiliki keunggulan dibanding asal-usulnya; lebih besar, kuat, cepat tumbuh, dan lebih resisten (melalui Damono, 1999:viii).

Hibrida genetika itu analog dengan hibrida sastra. Jika mencermati asal-usul bahasa dan sastra, maka dapat disimpulkan bahwa sastra modern adalah sastra hibrida, sastra hasil penyilangan dari berbagai bahasa dan kebudayaan. Menurut Damono, sastra Indonesia modern adalah sastra hasil penyilangan, baik alamiah maupun rekayasa, dari berbagai bahasa dan kebudayaan yang ada di Indonesia, bahkan dari berbagai bahasa dan kebudayaan yang ada di dunia. Sastrawan Indonesia modern hakikatnya menggunakan sekaligus menciptakan bahasa Indonesia. Sastra Indonesia modern, seperti halnya bahasa Indonesia, tidak lagi menjadi milik orang Melayu, tetapi juga milik orang Aceh, Sunda, Jawa, Bali, Dayak, Madura, Bugis, Papua, dan sebagainya. Semua orang Indonesia - tidak terkecuali sastrawan yang berasal dari berbagai bahasa dan kebudayaan itu mempunyai hak dan kewajiban untuk mengembangkannya (1999:viii-ix). Dapat dibayangkan betapa rumitnya masalah yang timbul, terutama berkaitan dengan aspek-aspek linguistik dan ideologi dalam arti luas, termasuk kearifan lokal. Belum lagi fenomena asimilasi dengan berbagai bahasa dan kebudayaan asing 
yang ada di seluruh dunia, nyata-nyata sastra Indonesia telah menjadi warga sastra dunia. Jika masalah itu dapat diatasi, dapat dibayangkan betapa kaya sastra Indonesia di masa depan.

\section{Kearifan Lokal dalam Hibriditas Sastra Indonesia Modern}

Berikut ini adalah beberapa contoh, berupa penggalan beberapa satra hibrida, dari yang hibriditasnya sederhana sampai yang ekstrem.

(1)

Berdiri aku di senja senyap

Camar melayang menepis buih

Melayah bakau mengurai puncak

Berjulang datang ubur terkembang

("Berdiri Aku", Amir Hamzah)

(2)

Sepi di luar, sepi menekan mendesak

Lurus kaku pepohonan. Tak bergerak

Sampai ke puncak

Sepi memagut

Tak suatu kuasa berani melepas diri

Segala menanti. Menanti menanti

Sepi.

Dan ini menanti penghabisan mencekik

("Hampa", Chairil Anwar)

\section{(3)}

Isteri mesti digemateni

Ia sumber berkah dan rejeki

(Towikromo, Tambran, Pundong, Bantul)

Isteri sangat penting ngurus kita

Menyapu pekarangan

Memasak di dapur

Mencuci di sumur

Dan ngeroki kita kalau kita lagi masuk angin

Ya. Ya. Isteri sangat penting bagi kita justru ketika kita mulai melupakannya.

Jadi waspadalah!

Tetep, madhep, manteb

Gemati, nastiti, ngati-ati

("Isteri", Darmanto Jatman) 
(4)

hei Kau dengar manteraku

Kau dengar kucing memanggil-Mu

izukalizu

$\mathrm{M}$ a p a k a s a b a isatasali

tutulita

pailiko arukabazaku kodega zuzukalibu

tutukaliba dekodega lagotokoco

zukuzangga zegezegezege zukuzangga zege

zegeze zukuzangga zegezegeze zukuzang

(“Amuk", Sutardji Calzoum Bachri)

(5)

Amplop keempat: "Yassiru walaa tu'assiruu! (Berikan yang mudah-mudah dan jangan mempersulit!) Duduk Gresik, 4 Januari 2002”.

Dan amplop kelima" "Ya ayyuhalladziina aamanuu lima taquuluuna malaa taf'aluun?. Kabura maqtan 'indaLlahi an taquuluu malaa taf'aluun! (Hai, orangorang yang beriman, mengapa kamu mengatakan sesuatu yang kau sendiri tak melakukannya. Besar sekali kebencian di sisi Allah bahwa kamu mengatakan sesuatu yang kau sendiri tak melakukannya!). Batanghari, Lampung Timur, 29 April 2002”.

Aku mencoba mengingat-ingat apa saja yang pernah aku ceramahkan di tempat-tempat di mana aku menerima amplop-amplop itu ("Amplop-amplop Abuabu” Mustofa Bisri).

Eskalasi perkembangan hibriditas sastra pada contoh di atas berbanding lurus dengan eskalasi transformasi budaya yang berlangsung terus-menerus dengan percepatan semakin tinggi. Struktur dan esensi puisi Chairil Anwar sebagaimana terlihat pada penggalan (2) tidak akan tercipta jika Chairil tidak meresepsi kepenyairan H. Marsman dan Archibald McCleish, seperti halnya Amir Hamzah juga tidak akan mencipta "Berdiri Aku" seandainya ia tidak tergetar oleh makna su'ur (syair) sufi Raja Ali Haji. Sajak "Isteri” mustahil lahir kalau Darmanto Jatman tidak mengenal akrab puisi multilingual para penyair imigran di Amerika yang berkembang sekitar tahun tujuhpuluhan. Mantra Sutardji pada sajak "Amuk" juga tidak akan ada tanpa obsesi pembebasan kata dari jajahan makna, sebagaimana telah diperlihatkan oleh puisi "credo" dan visual poem Prancis yang dipelopori Charles Boudellaire. Cerpen “Amplop-amplop Abu-abu” dimungkinkan tercipta karena memang kepengarangan Mustofa 
Bisri berada dalam kebudayaan "ulang-alik" (istilah Sapardi Djoko Damono) antara tradisi syiar (baca: spirit keustadzan) dan syair (baca: spirit kepenyairan).

Berikut adalah beberapa contoh penggalan sastra yang hibriditas kebahasaannya rumit.

(6)

Derrtt... HP-nya kembali bergetar. Ada SMS yang mampir di-inbox-nya.

Woi, ank ktu. HP lo sbk bgt!

Felix da call, ya?

Dari Marcia. Rhea segera membalasnya.

Ud. Lo gk ush ganggu gw $1 g \mathrm{~d}$ !

Bsh gw crt, jnji! Skrg gw mo

Bljr geo dl ne! oc.

HP-nya kembali bergetar membuyarkan lamunan Rhea. SMS dari Marcia.

Yg da pny gebetan, tmn dilupain.

Bljr lo sana. Bsk sontkn hrs mmpir d mj gw! Awsss lo!

Ada SMS. Rhea membuka pesan itu.

Hi, sweety! Lg ngpain? Gw lg mkrin lo, ne.

Kangeeeen... bgt!

Dari Felix! Senut-senut di kepalanya langsung sirna nggak berbekas. Sekarang jantungnya jadi berdebar-debar. Rhea segera mengetik message balasan untuk Felix.

Kpl gw lg skt bgt.

Ptma kli les gw dsiksa abs2an ma gurunya.

Skrg kpl gw mo pch.

(Nggak Usah Jaim, Deh!, Valleria Verawaty, h. 90-91).

Penggunaan kata-kata "aneh" yang tidak lazim dipakai sebagai alat komunikasi, bagi komunitas tertentu (misalnya remaja) menjadi alat legitimasi mengukuhkan status dalam komunitas yang bersangkutan. Cakapan dengan bahasa $S M S$ atau BBM pada kutipan (6) mengisyaratkan bahwa produk teknologi informasi telah mengubah sistem dan gaya tutur pemakainya. Lambang-lambang bunyi bahasa yang lazim disusun berdasarkan sistem dan kaidah yang konsisten sehingga terbentuk morfem, kata, frasa, klausa, kalimat, paragraf yang terstruktur dan bermakna diubah semena-mena tanpa sistem dan kaidah yang jelas. Fasilitas fitur fontasi dan auto-image ponsel meleluasakan penggunanya mengeksplorasi kreativitas menulis lambang-lambang bunyi dan gambar sesuai selera keunikannya, semakin unik dianggap semakin bernilai. Akibatnya, deviasi penulisan bahasa yang berupa kata, istilah, kalimat, dan paragraf pada bahasa $S M S$ atau $B B M$ terjadi secara ekstrem. Contohnya, kata 
"gue" dituliskan "gw", kata "buat" dituliskan "bwt", kata "nih" dituliskan "ne", kata "see you" dituliskan "c u", kata "school” dituliskan "skul”, kata "aku” dituliskan "Q" atau"q", dan sebagainya. Perubahan itu tidak hanya menyangkut penulisan ejaan (huruf dan pungtuasi) saja, tetapi juga menyangkut penulisan lambang bunyi, misalnya penulisan huruf kapital yang tidak lazim. Contohnya, kata "Bu Guru Rosi” dituliskan "bGRu rOZi, dan sebagainya. Kecanggihan fasilitas fontasi pada komputer, ponsel, dan perangkat multimedia lain benarbenar telah memanjakan penutur untuk mengaduk-aduk (terutama lambang) bahasa dengan semena-mena. Faktanya, berbagai deviasi itu tidak dianggap "mencemarkan" status dan kredibilitas penuturnya, sebaliknya malah dianggap sebagai cyberholic, dan secara eksplisit justru menumbuhkan kesan kekaguman dalam pandangan kalangan komunitasnya, ada keberterimaan sosial.

\section{Simpulan}

Sastra hibrida dengan bermacam variabel itu sebenarnya tetap mengakar pada budaya etnik penciptanya. Amir Hamzah, Chairil Anwar, Darmanto Jatman, Sutarji Calzoum Bachri, Mustofa Bisri, Valleria Verawaty sebatas memperbarui cara pengungkapan gagasan. Secara esensial mereka tetap berpijak pada tradisi dan budaya yang melahirkannya. Nilai-nilai Islam pada sajak-sajak Amir Hamzah adalah Islam-Melayu, bukan Islam-Arab; nilai kebersahajaan pada sajak-sajak Darmanto adalah nilai-nilai kebersahajaan manusia Jawa, bukan egalitarian; nilai humanisme pada cerpen-cerpen Mustofa Bisri adalah nilai-nilai kemanusiaan orang Jawa yang rendah hati dan tepa-slira; sikap dan perilaku "semau gue" pada novel-novel Valleria Verawaty adalah representasi nilai-nilai kepedulian, kebersamaan, dan kedekatan emosi yang asli dimiliki para remaja kita, bukan individualisme dan egoisme remaja Amerika. Apa pun bentuk sastra kita tercipta dan ke mana pun sastra kita berubah langkah, kearifan lokal setia mengikutinya. 


\section{Daftar Pustaka}

Ardelia, Maria. 2005. Me Versus High Heels (cetakan ke-16). Jakarta: Gramedia Pustaka Utama.

Bachri, Sutardji Calzoum. 1981. O, Amuk, Kapak (Kumpulan Puisi). Jakarta: Sinar Harapan.

Bisri, Mustofa. 2008. Lukisan Kaligrafi: Kumpulan Cerpen (cetakan ke-3). Jakarta: Penerbit Buku Kompas.

Damono, Sapardi Djoko. 1999. Politik, Ideologi, dan Sastra Hibrida. Jakarta: Pustaka Firdaus.

Damono, Sapardi Djoko. 2009. Sosiologi Sastra: Pengantar Ringkas. Jakarta: Editum.

Kayam, Umar. 1982. "Multilingualisme dalam Sastra” dalam Satyagya Hoerip (ed.). Sejumlah Masalah Sastra. Jakarta: Sinar Harapan.

Noor, Redyanto. 1999. Perempuan Idaman Novel Indonesia: Erotik dan Narsistik. Semarang: Bendera.

. 2014. "Gerak Perlawanan Budaya: Produksi, Distribusi, Resepsi, dan Pergeseran Nilai Gaya Hidup Remaja dalam Novel Chicklit dan Teenlit Indonesia", Disertasi Program Doktor, Fakultas Ilmu Budaya Universitas Gadjah Mada, Yogyakarta.

Verawaty, Valleria. 2005. Nggak Usah Jaim, Deh! (cetakan ke-8). Jakarta: Gramedia Pustaka Utama. 